\title{
Heat Treatment of Recycled Battlefield Stainless-Steel Scrap for Cold Spray Applications
}

\author{
CHRISTOPHER MASSAR, ${ }^{1}$ KYLE TSAKNOPOULOS, ${ }^{1}$ \\ BRYER C. SOUSA, ${ }^{1}$ JACK GRUBBS,${ }^{1}$ and DANIELLE L. COTE $\mathbb{B}^{1,2}$ \\ 1.-Worcester Polytechnic Institute, Worcester, MA 01609, USA. 2.-e-mail: dlcote2@wpi.edu
}

\begin{abstract}
This work explores the impact of thermally preprocessing recycled austenitic stainless-steel powder for solid-state cold spray metal additive manufacturing with a focus on increasing deposition quality and coating density while maintaining mechanical integrity. The recycled stainless-steel scrap was gasatomized using a novel mobile foundry manufactured by MolyWorks Materials Corporation. The powder was thermally treated based upon thermodynamic modeling using Thermo-Calc. The powder and sprayed specimens were characterized using particle size-shape analysis, microscopy, $\mathrm{x}$-ray diffraction, and nanoindentation. Diffraction results highlighted the presence of both austenite and ferrite phases in the powder. Nanoindentation confirmed that thermally processing the feedstock powder at the austenitization temperature decreased the amount of ferrite present, which was consistent with the porosity observed in the deposits due to the lower yield strength of austenite relative to ferrite. The untreated powder deposits exhibited extensive porosity and microcracking, as opposed to the virtually fully dense deposit from the heat-treated powder.
\end{abstract}

\section{INTRODUCTION}

Cold-gas dynamic-spray (cold spray) is a solidstate materials consolidation technology that utilizes particulate feedstock, which is transported via a heated carrier gas stream until exiting a de Laval nozzle and supersonically impacting a substrate. While cold spray was originally conceptualized as a tool for achieving coatings with unique and application-specific properties, the process was adopted by the remanufacturing and repair, and the additive manufacturing (AM) communities. As ballistically impinged particles adhere to a substrate, particle-particle bonding occurs as the process continues to deposit powder layer by layer. Successful consolidation requires particle-substrate and particle-particle metallurgical and mechanical bonding. ${ }^{1}$

Cold spray parameters vary from the nozzle type to the selection of powder composition and gas source. Typically, inert gases are used, such as helium or nitrogen. Feedstock powder for cold spray typically has a diameter range from approximately
$5 \mu \mathrm{m}$ to $100 \mu \mathrm{m}$. Particles achieve velocities between $300 \mathrm{~m} / \mathrm{s}$ and $1200 \mathrm{~m} / \mathrm{s}$ with associated pressures under 300 psi for low-pressure cold spray (LPCS) and above for high-pressure cold spray (HPCS). Many materials can be cold sprayed, including polymers, composites, copper, aluminum, steel, and titanium, and are chosen according to the application and the necessary part performance. ${ }^{1}$

Since cold spray is a solid-state process, the properties of the feedstock directly influence the properties of the component., ${ }^{2,3}$ Given this, it is important to understand and control the feedstock properties prior to deposition. One way to control powder properties is through the manipulation of the internal microstructure. This can be done via heat treating. ${ }^{4-9}$ Thermal treatments of powder must be customized since the kinetics associated with powder are more rapid versus their bulk counterparts. ${ }^{10,11}$ Heat treatment allows for the control of secondary phases and grain size, which can change the relevant powder properties. Property manipulation can also increase cold spray deposition efficiency. 


\section{Powder Production for Cold Spray}

Given the diverse nature of powder-based AM, various powder production methods have been developed. For metal powders, production methods can be categorized into two groups: mechanical and chemical methods. Mechanical methods-including atomization, milling, and mechanical alloying-involve the disintegration of hard metals into powders, or the formation of powders from a molten metal pool. Chemical methods-including electrolysis and reduction-produce powders by extracting the metal from another component, such as a metal oxide or a salt from an aqueous solution. ${ }^{12,13}$ While chemical methods produce high-purity powders, they are limited by slow production rates, high costs, and environmental safety concerns; thus, mechanical methods are preferred on an industrial scale. ${ }^{13}$ When considering the mechanical production of metal powders, atomization techniques are often utilized, as they have high production rates and provide the most versatile particle size distribution (PSD). ${ }^{13}$ Atomization will be considered in this discussion due to its versatility.

Metal atomization refers to the breakup of molten liquid into fine droplets, which rapidly solidify as powder particles. This produces powder with a predictable and controllable PSD. Fluid-based atomization is the most common technique, where the liquid metal is scattered into discrete droplets by a high-pressure stream of gas or water. ${ }^{14}$ These powders are typically characterized by log-normal PSD, low surface areas, and minimal porosity. Depending on the fluid stream used, powder sizes and shapes can range from small and spherical to large and irregular. For example, water atomization-often used with ferrous materials due to costeffective production-results in irregularly shaped powder with relatively high surface oxygen concentrations. ${ }^{13}$ Cold spray has the ability to utilize powder created by various types of manufacturing for a variety of applications with numerous material systems.

\section{COLD SPRAY APPLICATIONS}

Cold spray has been applied to many manufacturing sectors of the global economy. Antimicrobial surfaces have been created using copper cold spray. ${ }^{15}$ Medical stints were produced using steel cold spray. ${ }^{16-19}$ Research efforts have focused upon nickel-alumina cold spray for solar energy absorption. ${ }^{20}$ Cold spray has also been used in a variety of defense-related applications. Given the corrosion associated with magnesium aircraft components employed by the US Army and Naval forces, cold spray has been applied to the reclamation and repair of parts. ${ }^{21}$ Cold spray was utilized by Department of Defense (DoD) researchers in electromagnetic interference shielding components. ${ }^{22}$ Gun barrel liners have been fabricated using tantalum cold spray. ${ }^{23}$
Motivation for this work derives from the push for in-theater repair to reduce component downtime. A logistical threat to the warfighter stems from broken equipment, where the need for in-theater repair is paramount to their success. ${ }^{24-26}$ While qualifications for DoD applications tend to be a slow process, the use of cold spray should see decreased qualification times. $^{27}$ This is evident with the relatively rapid qualification for the repair of the main transmission housing for the H-60 helicopter that demonstrated significant cost and time savings. ${ }^{28}$

One of the greatest threats to mission preparedness of the warfighter is downtime of quintessential equipment, which endangers those fighting on the front line. Many of the options that currently exist involve either having parts manufactured and shipped or having stock material shipped in so that parts can be machined in-theater. The MolyWorks Mobile Foundry, created by MolyWorks Materials Corporation, mitigates many of these logistical issues by producing feedstock powder, on site, from indigenous material. ${ }^{24-26}$ The Mobile Foundry uses a patented cold hearth technology, allowing for the processing of a variety of materials including aluminum, steel, and titanium alloys to produce powder with homogeneous properties from both traditional stock material and recycled battlefield scrap material.

\section{Steel Cold Spray Consolidation}

Austenitic stainless steels have exceptional thermal properties and corrosion resistance at elevated temperatures and are an essential structural material for military applications. ${ }^{29}$ Composition plays an integral role in the phase stability, which can change based on the ratio of nickel to chromium. These phase types include ferritic, ferritic-austenitic, austenitic-ferritic, and austenitic for traditional continual casting, ${ }^{30}$ with similar phases present in rapidly solidified stainless steels. Nickel and manganese additions can promote austenite stabilization. ${ }^{31}$ Iron, chromium, and molybdenum are ferrite formers; when rapidly cooled they can produce martensite and or ferrite. ${ }^{32}$

Due to the susceptibility to strain hardening and resistance to plastic deformation, the development of austenitic stainless-steel cold spray has been limited. ${ }^{33,34}$ Meng et al. studied the effect of gas temperature on the properties of 304 stainless steel deposited via cold spray. ${ }^{35}$ Codder et al. considered 304L stainless-steel cold spray to understand the influence of helium carrier gas upon the mechanical properties. ${ }^{36}$ Brewer et al. worked towards developing a framework for understanding the significance of varied austenitic stainless-steel feedstock powder properties in terms of the cold spray of microstructure. ${ }^{37}$ Additional research has been conducted on 316L stainless steel for cold spray. ${ }^{38-44}$ 


\section{MATERIALS AND METHODS}

\section{Powder Production}

Austenitic stainless-steel powder was produced by gas atomization by the MolyWorks Materials Corporation (Cloverdale, CA) from recycled battlefield 316 and 304 stainless-steel scrap metal. The deployable foundry designed to be fully encapsulated within a shipping container melts 6" chunks of scrap using a plasma torch in a mixing hearth, which is then subsequently passed over an inert argon stream and collected using a cyclone collection system. The composition of the stainless-steel feedstock was measured via direct-current plasma emission spectroscopy and combustion infrared detection (Luvak Laboratories, Inc., Boylston, MA). ${ }^{45,46}$ Table I presents the chemistry of the stainless-steel powder and is compared with standard compositions for 316 and 304 stainless-steel. ${ }^{47}$ The material in this work is compositionally more similar to 304 stainless steel; however, it was melted from battlefield scrap with a $\mathrm{Cr}$ content of $17.42 \%$, which is low for 304 , but within specification for 316 , and an Mo content of $0.12 \%$, which is low for 316 and within specification for 304 .

\section{Thermal Processing of the Powder}

The computational thermodynamic software, Thermo-Calc (Solna, Sweden), was used to understand the thermal stability of the phases present. The TCFE9 database was utilized for the creation of an equilibrium diagram for the powder feedstock using the composition from Table I.

For laboratory-scale austenitization of the powder, $20-\mathrm{mg}$ to $30-\mathrm{mg}$ batches were heat treated using a thermogravimetric analyzer (TGA) (TA Instruments, New Castle, DE). The TGA enabled precise control of the processing time and temperature. The thermal ramp rate was $200^{\circ} \mathrm{C} \mathrm{min}^{-1}$ under a flow of argon gas at $45 \mathrm{ml} \mathrm{min}{ }^{-1}$ using a platinum pan. The austenitization temperature, $840^{\circ} \mathrm{C}$, was held for $0 \mathrm{~min}, 5 \mathrm{~min}, 10 \mathrm{~min}, 15 \mathrm{~min}$, and $20 \mathrm{~min}$.

Industrial-scale processing of the powder was performed using a stainless-steel tube furnace (Solvus Global LLC, Worcester, MA); two pounds of powder were thermally treated. A thermal ramp rate of $26^{\circ} \mathrm{C} \mathrm{min}{ }^{-1}$ was employed until a temperature of $840^{\circ} \mathrm{C}$ was achieved. The material was held in an argon atmosphere for $20 \mathrm{~min}$ and subsequently cooled at a rate of $4^{\circ} \mathrm{C} \mathrm{min}^{-1}$. Data acquisition was carried out using a programmable logic controller (PLC) (Siemens AG, Munich, Germany).

\section{Characterization}

X-Ray diffraction (XRD) was performed using the Empyrean x-ray diffractometer (Malvern Panalytical Ltd., Almelo, Overijssel, the Netherlands). XRD results were analyzed using HighScore Plus software.

PSD and morphology analysis was performed using a Microtrac TurboSync system (Microtrac Retsch GmbH, Haan/Duesseldorf, Germany).

Powder and cold-sprayed samples were compression mounted in a phenolic resin using a Buehler Simplimet 4000 system (Lake Bluff, IL). Grinding and polishing were carried out in accordance with standard metallographic techniques using a Buehler Ecomet 300 grinder-polisher. The final polish was achieved using a $0.05 \mu \mathrm{m}$ colloidal silica suspension.

A scanning electron microscope (SEM), Evo MA10 SEM (Carl Zeiss AG, Oberkochen, Germany), was used to obtain micrographs of the specimens, and a Bruker X Flash EDS Detector $630 \mathrm{M}$ (Bruker Nano GmbH, Berlin, Germany) was used for elemental analysis. Optical microscopy was performed using a GX71 inverted metallurgical microscope (Olympus Corporation, Shinjuku City, Tokyo, Japan). Image analysis of the micrographs was conducted using the Olympus Stream software with contrast thresholding.

Nanoindentation testing was performed with the iMicro Pro (Nanomechanics, Inc., Oak Ridge, TN) with an InForce 50-mN actuator. The actuator was equipped with a Berkovich diamond indenter tip (Micro Star Technologies Inc., Huntsville, TX). The Oliver-Pharr method was employed during the contact area function calibration process, and the hardness was reported at a depth of $\sim 250 \mathrm{~nm}$. The maximum applied load was held for $15 \mathrm{~s}$. Spacing between indents was sufficiently large to ensure

Table I. Composition of the stainless-steel powder used in this work, compared with the ASTM standards for 316 and 304 stainless steels

\begin{tabular}{|c|c|c|c|c|c|c|c|c|c|c|}
\hline Elements (wt.\%) & $\mathbf{F e}$ & $\mathbf{C}$ & $\mathbf{C r}$ & Mn & Si & Mo & $\mathbf{P}$ & $\mathbf{N i}$ & $\mathbf{S}$ & $\mathbf{N}$ \\
\hline Experimental stainless-steel powder & Bal. & 0.05 & 17.42 & 1.37 & 0.35 & 0.12 & 0.03 & 8.07 & 0.0005 & - \\
\hline ASTM standard $316^{47}$ & Bal. & 0.08 & $16-18$ & 2.00 & 0.75 & $2-3$ & 0.045 & $10-14$ & 0.03 & 0.1 \\
\hline ASTM standard $304^{47}$ & Bal. & 0.08 & $18-20$ & 2.00 & 0.75 & - & 0.045 & $8-11$ & 0.03 & 0.1 \\
\hline
\end{tabular}


that the hardening zones did not interact. A Poisson's ratio of 0.27 was assumed. Microhardness was conducted using a Wilson VH3300 indentation system (Buehler, Lake Bluff, IL).

\section{Cold Spray Deposition and Parameters}

An automated VRC GEN III cold spray system (VRC Metal Systems, Box Elder, SD) was used for the deposition of the stainless-steel powder and was equipped with either a polybenzimidazole (PBI) or tungsten carbide (WC) nozzle. While initial HPCS depositions were carried out using a 0.75$5 \times 180 \mathrm{~mm}$ water-cooled WC nozzle with the parameters summarized in Table II, a more successful HPCS deposition was completed using a PBI nozzle following a proprietary set of spray parameters developed by MOOG, Inc. (Elma, NY). Material consolidation was performed at the Cold Spray Synergy Site (Webster, MA, USA).

\section{RESULTS AND DISCUSSION}

The morphology and PSD of the powder are shown in Fig. 1. The powder demonstrated the strongly skewed distribution depicted in Fig. 1a, in agreement with the powder being sieved to $45 \mu \mathrm{m}$ and the fact that the fine particles were not removed. This practice is in accordance with prior work concerning powder preparation for cold spray. ${ }^{48}$ Particle morphology was classified as irregular using particle outlines from the Microtrac data and SEM micrographs shown in Fig. 1c-e, where a combination of spherical and nonspherical geometries are present. As the particle size decreased, the likelihood of a particle being spherical increased. Also, the likelihood of a particle having an irregular, nonspherical shape increased as the particle size increased. This is demonstrated in Fig. 1b, c where Fig. 1b demonstrates the large, irregular particles, while Fig. 1c demonstrates the smaller, more spherical particles.

The existing variation in particle size and geometry-with small spherical particles and large irregular particles-may prove advantageous in cold spray processing. When small spherical powders are present, researchers have observed that they act as "fillers" between larger particles and promote increased coating densification. ${ }^{49,50}$ Irregularly shaped particles have been shown to achieve greater velocities than spherical particles. ${ }^{51}$ As a result, enhanced particle-particle interfacial bonding can be achieved. ${ }^{52}$ Even though small spherical particles have been shown to be beneficial for increased deposition efficiency and enhanced coating densification, there also exists a lower limit to the particle sizes that are optimal for cold spray.

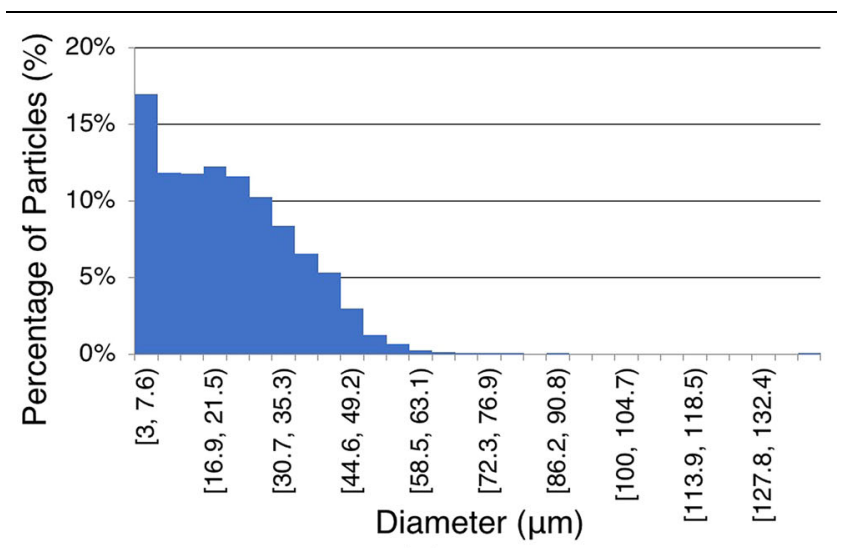

(a)

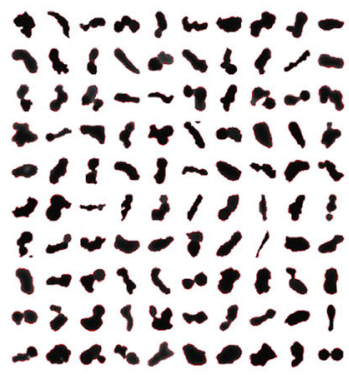

(b)

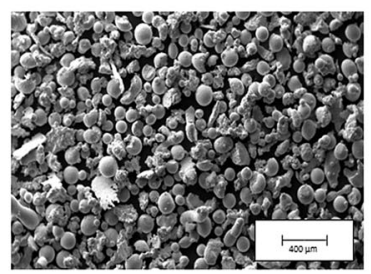

(d)

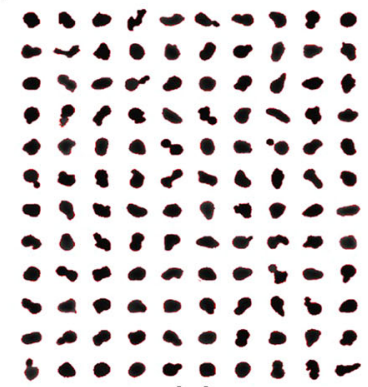

(c)

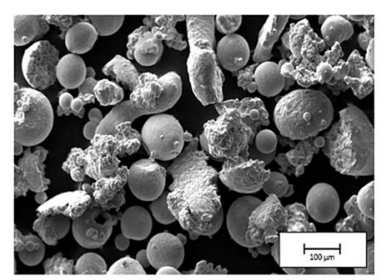

(e)
Fig. 1. (a) PSD of stainless-steel powder, (b, c) particle morphologies of the particulate feedstock, and (d, e) SEM micrographs of powder

Table II. Cold spray processing parameters

\begin{tabular}{|c|c|c|c|c|c|c|c|}
\hline Nozzle & $\begin{array}{l}\text { Gas temp. } \\
\quad\left({ }^{\circ} \mathbf{C}\right)\end{array}$ & $\begin{array}{l}\text { Carrier } \\
\text { gas }\end{array}$ & $\begin{array}{c}\text { Gas } \\
\text { pressure (psi) }\end{array}$ & $\begin{array}{l}\text { Spray } \\
\text { angle }\end{array}$ & $\begin{array}{c}\text { Standoff } \\
\text { distance }(\mathbf{m m})\end{array}$ & $\begin{array}{c}\text { Traverse speed } \\
\qquad(\mathrm{mm} / \mathrm{s})\end{array}$ & $\begin{array}{l}\text { Powder feeder } \\
\text { rate (RPM) }\end{array}$ \\
\hline $1 \mathrm{WC}$ & 425 & $\mathrm{He}$ & 435 & 90 & 25 & 25 & 3 \\
\hline $2 \mathrm{WC}$ & 600 & $\mathrm{He}$ & 435 & 90 & 25 & 25 & 3 \\
\hline 3 PBI & - & $\mathrm{He}$ & - & - & 25 & - & - \\
\hline
\end{tabular}


King and Jahedi demonstrated that insufficient particle deformation was associated with particle diameters below $5 \mu \mathrm{m}$ for aluminum and $2 \mu \mathrm{m}$ for copper. ${ }^{53}$ Since the ultrafine particles were not removed in this study, further investigation is needed to conclude whether increased coating density and deposition efficiency could be achieved.

The micrographs in Fig. 1d, e reveal the presence of particles with plate-like morphologies, in addition to the spherical and other irregular geometries. Energy-dispersive x-ray spectroscopy (EDS) revealed that, for particles with a plate-like geometry, there was a greater carbon content compared with the regularly shaped particles, with carbon weight percent between $23 \%$ and $35 \%$. The increased carbon content is likely due to residual oil from machined steel chips that could have contaminated the batch of battlefield stainless-steel scrap used to produce this powder. Removal or avoidance of these types of particles would likely also increase the coating density and deposition efficiency of the cold spray.

The resultant phases that form from rapid solidification of the molten powder droplets are dependent upon the degree of undercooling, atomization gas, and composition. ${ }^{54-65}$ Undercooling is notably associated with the quantity of ferrite and austenite nucleation. There exists an undercooling gradient within the powder particles; smaller powder particles cool faster than larger particles. In particular, ferrite will be more prominent within smaller particles due to the high degree of undercooling, whereas austenite will be highly concentrated within particles that have greater diameters. Since ferrite decreases the resistance to plastic deformation, it should be minimized. This can be achieved by thermally processing the gas-atomized powder.

Based on the powder composition, an equilibrium phase diagram was formulated with Thermo-Calc (Fig. 2a). Thermodynamic modeling assisted in the determination of the temperature required to achieve austenitization of the powder. It was determined that, if the austenitization of the atomized feedstock was performed above $840^{\circ} \mathrm{C}$, then all of the ferritic phase could, theoretically, transform to austenite. The austenitization temperature was also found suitable to avoid sintering particles by remaining below two-thirds of the melting temperature threshold. To avoid carbide growth, temperatures below $700^{\circ} \mathrm{C}$ were ruled out during the formulation of thermal processing parameters. ${ }^{66}$ Prior work established that the kinetics associated with thermal processing of micron-sized metallic powders is significantly more rapid than cast and wrought counterparts. ${ }^{10,11}$ Since the equilibrium diagram does not address the time required for microstructural transformation, laboratory-scale heat treatments at $840^{\circ} \mathrm{C}$ were performed in 5-min intervals, up to $20 \mathrm{~min}$, using the TGA. (a)
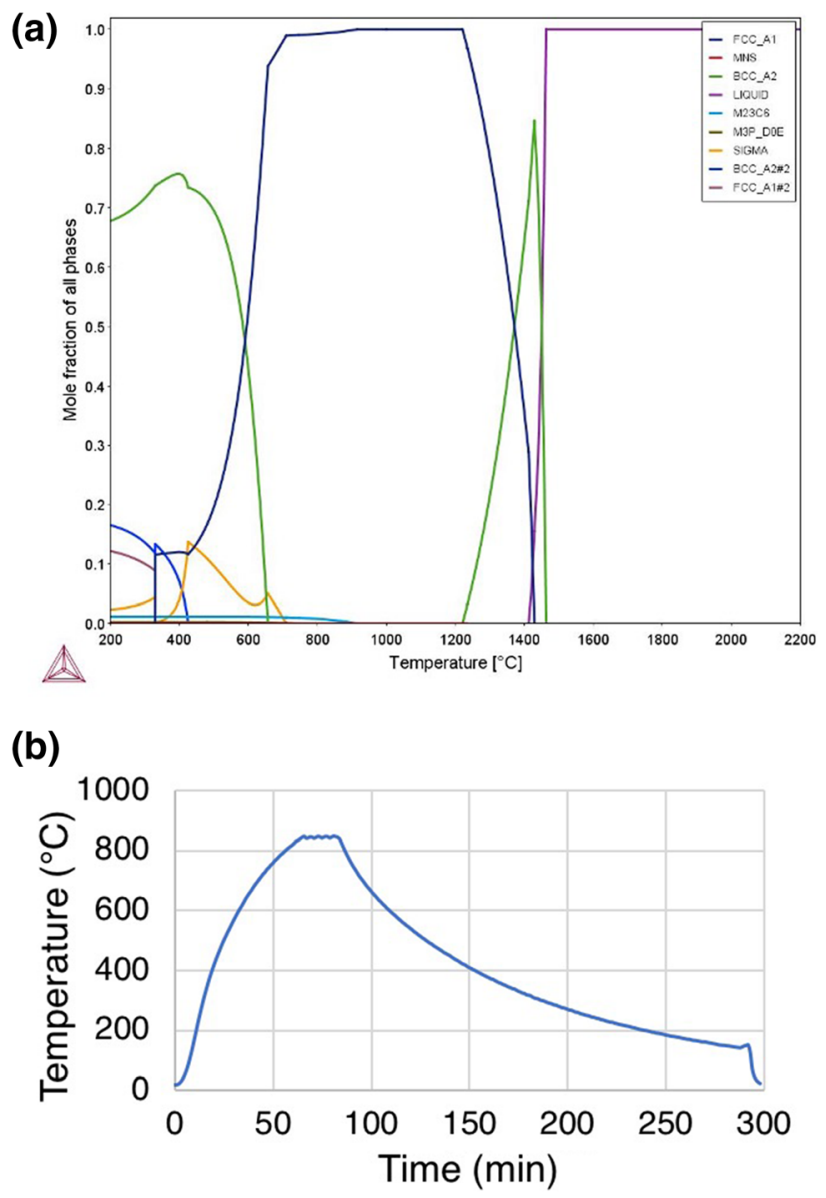

Fig. 2. (a) Thermo-Calc equilibrium diagram for stainless-steel powder, and (b) industrial-scale heat treatment cycle for the powder

To monitor the microstructure of the powders and their corresponding cold-spray consolidated specimens under various heat-treatment and spray conditions, their diffraction patterns were analyzed using XRD (Fig. 3). The pattern of the as-received (AR) powder indicates the presence of both austenite and ferrite. With increasing heat treatment time in the TGA, it was found that the relative intensity of the ferritic peak decreased. This was also demonstrated in the furnace-treated powder, where there was nearly complete elimination of ferrite. Coupling the XRD response of the laboratory-scale heattreated (HT) powder with the relatively slow cooling rates experienced when industrial-scale thermal processing was performed, as shown in Fig. 2, a hold time of $20 \mathrm{~min}$ at $840^{\circ} \mathrm{C}$ was found to be insufficient for complete austenitization, given the remaining ferrite present. While a carbide phase was indexed in all three of the powder conditions, the intensity of the peak remained constant throughout. Therefore, it stands to reason that the powder was austenitized without the deleterious effect of carbide growth, which has previously been touched upon as a concern within the cold spray community. ${ }^{67,68}$ 


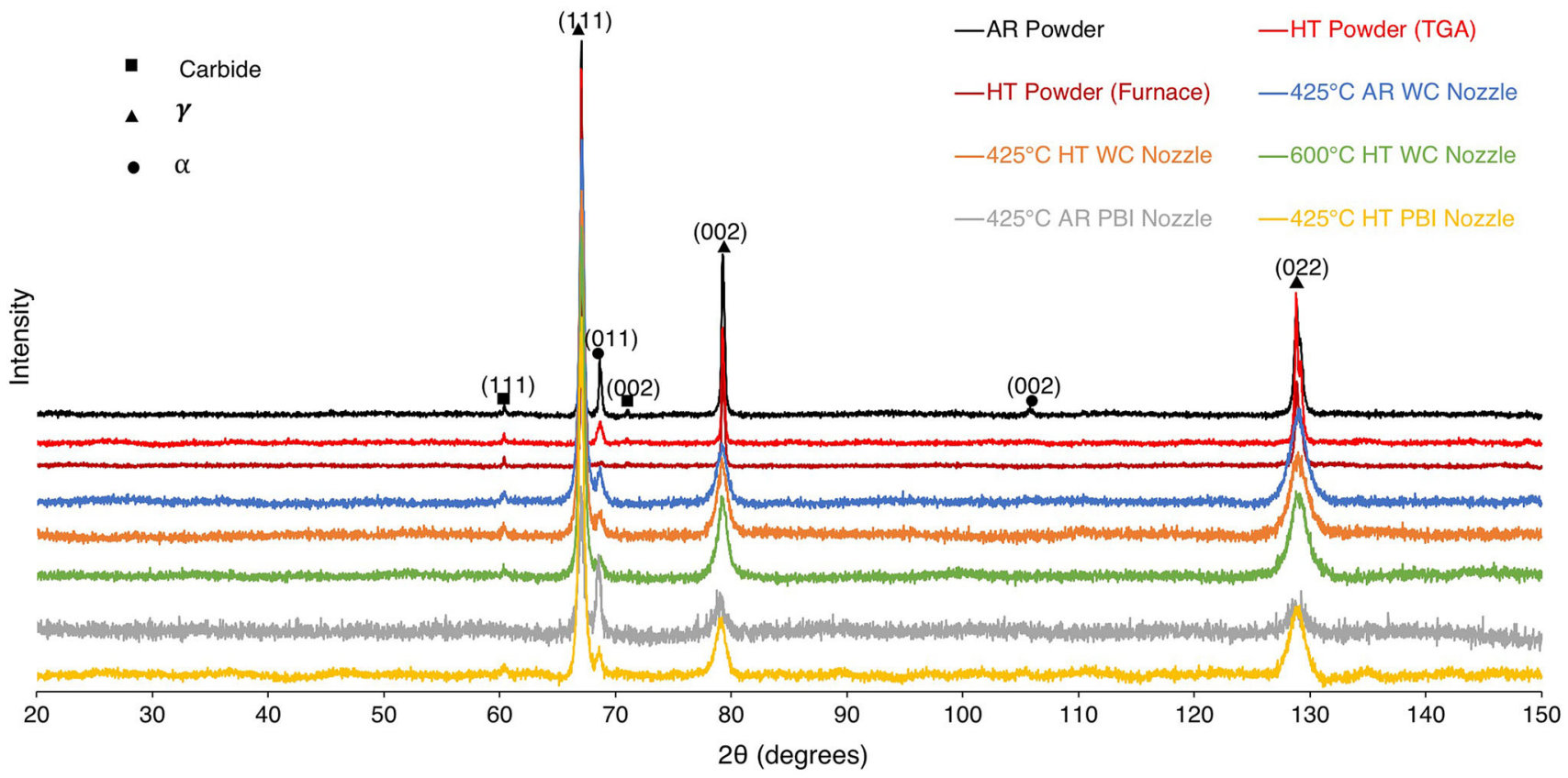

Fig. 3. XRD spectra for stainless-steel powders and cold-sprayed specimens under different heat-treatment and spray conditions

For the purpose of tailoring the thermal processing time to the kinetics associated with material at the micron length scale, dynamic nanoindentation testing was performed. Nanoindentation performed using the continuous stiffness measurement approach was employed as a methodology for evaluating the success achieved via austenitization of the powders as a function of holding time at the prescribed austenitization temperature. Using the TGA for laboratory-scale heat treatment of the powder at $0 \mathrm{~min}, 5 \mathrm{~min}, 10 \mathrm{~min}, 15 \mathrm{~min}$, and 20 min of austenitization time, nanoindentation of the processed powders revealed a nearly continuous decrease in hardness as the hold time was increased (Fig. 4). A decrease in hardness was found to correlate with an increase in the amount of austenite present and therefore a decrease in the amount of ferrite within the powder. Figure $4 \mathrm{a}-\mathrm{f}$ also shows SEM micrographs of the cross-sectioned particles at each time to qualitatively demonstrate the change in microstructure as a function of processing time.

Cold spray processing was performed using two different nozzles as shown in Table II, namely a WC nozzle and a PBI nozzle. Figure 5 demonstrates that greater porosity was observed when the powder was cold sprayed using a WC nozzle. Comparing the deposition at $425^{\circ} \mathrm{C}$ for the $\mathrm{AR}$ and $\mathrm{HT}$ powders in Fig. 4a and b, respectively, the AR powder appears to deposit more successfully, with smaller continuous pores throughout the specimen. When the HT powder was sprayed at $600^{\circ} \mathrm{C}$, the first deposition layer adhered to the substrate with relative success; however, fouling of the nozzle was observed despite the use of a water-cooled jacket attached to the WC nozzle, which resulted in the porous upper layer of
Fig. 5c. While deposition at $425^{\circ} \mathrm{C}$ was more successful for the AR powder, the results proved opposite with the use of the PBI nozzle. The PBI deposit of AR powder in Fig. 5d showed microporosity and macroscale cracking, while the PBI deposit of HT powder in Fig. 5e demonstrated no visible porosity or cracking. Those measurements are quantified in Fig. 6a.

The large-batch powder heat treatment carried out by Solvus Global produced a microstructure with modulus and hardness very similar to the 0 min run. This austenitization heat treatment produced significantly greater deposition characteristics reflected in the consolidated features in Figs. 5 and 6. While it is understood that the reaction kinetics in powder are different compared with their bulk counterpart, as discussed previously in this paper, further investigations need to be carried out for optimization in large-scale treatments. It is speculated that the prolonged cooldown time contributed to the discrepancy in this scaled-up process.

The AR and HT powders were sprayed using multiple nozzles and spray temperatures on the VRC GEN III system. The AR deposits exhibited extensive porosity and microcracking, as opposed to the virtually fully dense deposit from the HT powder. Increased deposition efficiency and coating density were also seen when using the PBI nozzle for spraying instead of the WC nozzle. The porosity, nanoindentation hardness, and microhardness values for the consolidated materials as a function of orientation relative to the spray direction, as well as processing parameters, are quantitatively illustrated in Fig. 6. 


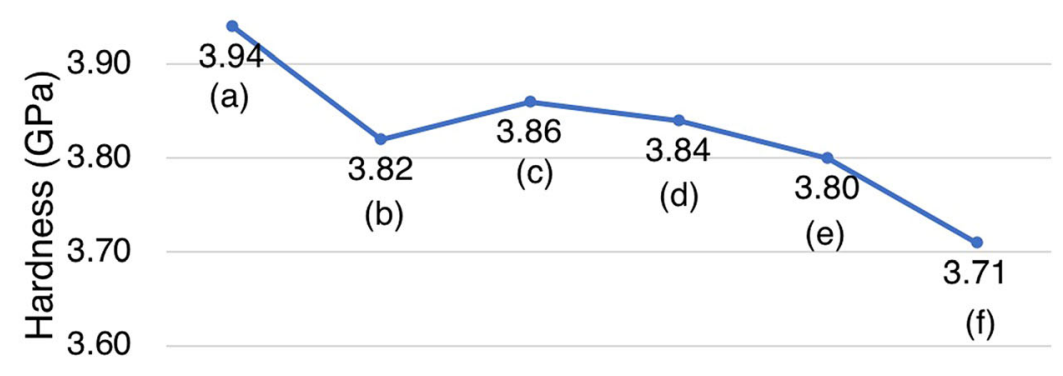

3.50

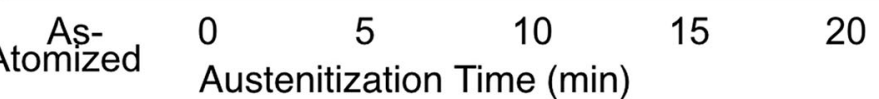

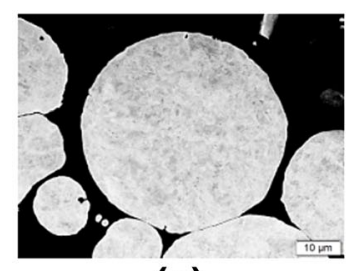

(a)

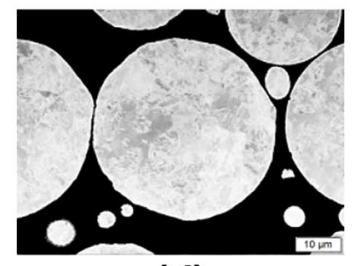

(d)

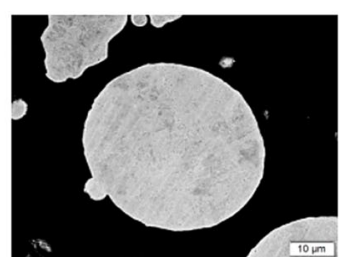

(b)

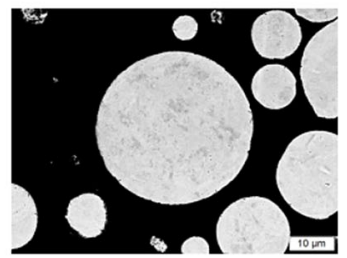

(e)

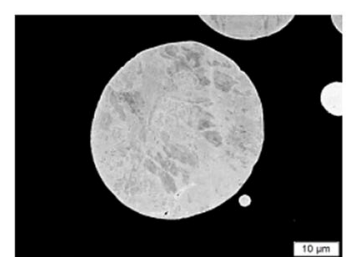

(c)

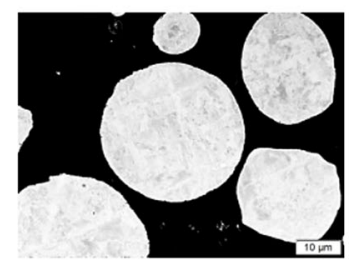

(f)

Fig. 4. Dynamic nanoindentation hardness of the powder particles as a function of austenitization time: (a-f) cross-sectional SEM micrographs of the powder for each time interval for (a) as-atomized powder, (b) ramped to $840^{\circ} \mathrm{C}$ and immediately cooled, (c) ramped and held for 5 min, (d) ramped and held for $10 \mathrm{~min}$, (e) ramped and held for $15 \mathrm{~min}$, and (f) ramped and held for $20 \mathrm{~min}$

Even though the AR cold-sprayed consolidation achieved generally successful deposition with markedly better coherency between particles, the HT powder achieved a virtually fully dense deposit with $50 \%$ less porosity than that of the AR cold-sprayed deposit, as shown in Fig. 6a, b. Furthermore, in the context of previous work concerning the development of steel cold spray, the thermally preprocessed powder and PBI nozzle achieved a porosity of $0.10 \%$, which is notably lower than the porosity of coatings reported in literature. ${ }^{33}$

Microhardness was used to target the bulk properties of the steel, while nanoindentation was used to quantify with higher precision the presence of varying phases. As the deposition process is highly kinetic, it is expected that the hardness values in relation to spray and traverse direction would yield anisotropic properties. Figure 6c reports measurements perpendicular to the traverse direction, and while not shown here, the measurements across the parallel and $z$ direction (top-down) agreed within the variation in the error bars presented in Fig. 6c.
Consistent with the trends in porosity in Fig. 6a, $b$, the microhardness shown in Fig. 6c demonstrates a significantly reduced variance in the samples deposited using the PBI nozzle as compared with those deposited using the WC nozzles. Figure $6 \mathrm{c}$ also shows a comparison of the hardness recorded by nanoindentation and microindentation. The drastic increase in nanoindentation hardness relative to microhardness is indicative of the wellknown "indentation size effect"; indenting the stainless-steel cold spray coatings at depths greater than $2 \mu \mathrm{m}$ will allow the "true" material hardness to be measured without the need for Nix-Gao analysis of the hardness versus depth data. This measurement can prove beneficial in tailoring preprocessing powder parameters such that the powder feedstock can be sprayed to have predictable and controllable mechanical properties without postprocessing and will be explored in future work.

XRD analysis of the deposited AR and HT powder elicited the presence of a (001) plane, demonstrating the potential presence of martensite. The dramatic (001) peak and presence of a (002) peak in the AR 


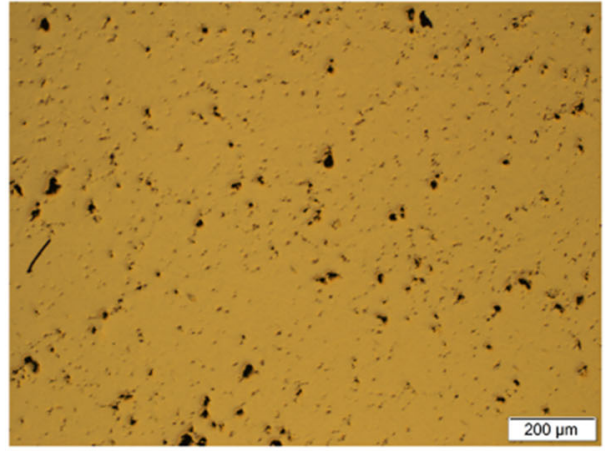

(a)

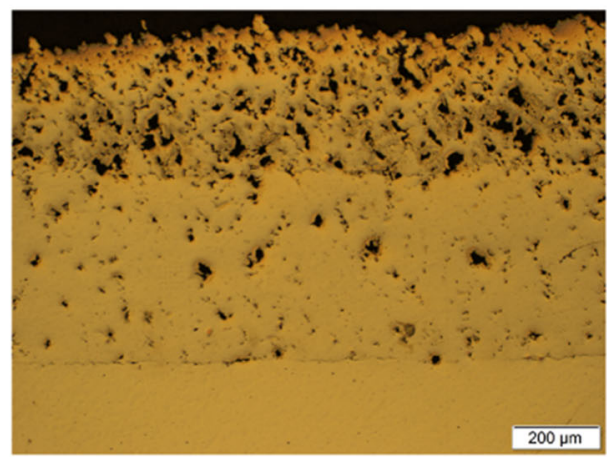

(c)

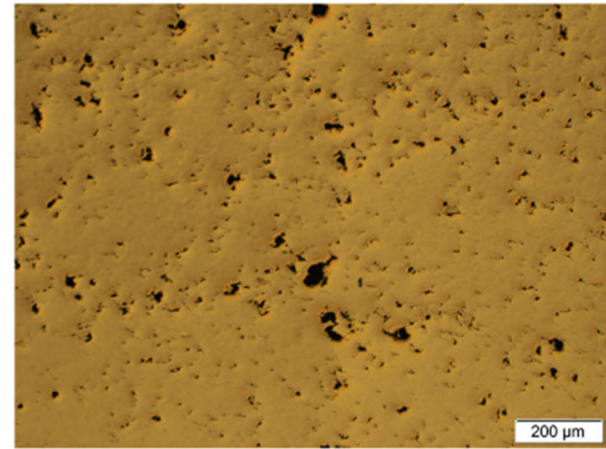

(b)

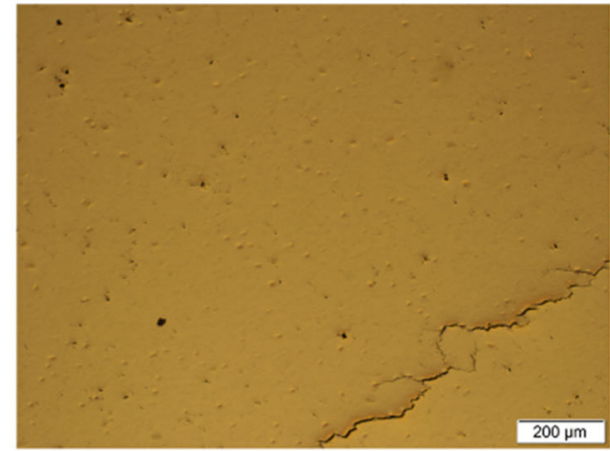

(d)

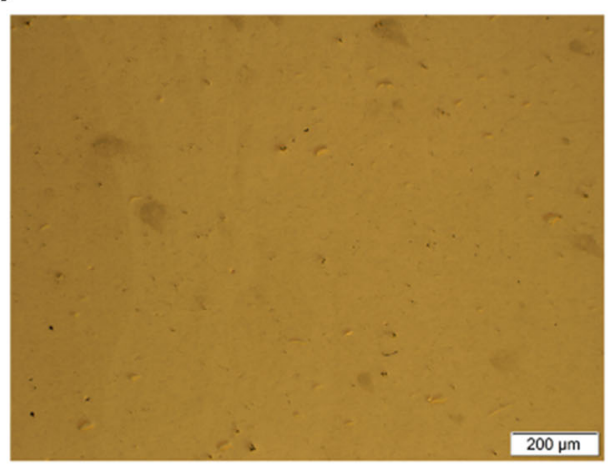

(e)

Fig. 5. Optical micrographs of consolidated depositions with varying processing parameters: (a) $425^{\circ} \mathrm{C} \mathrm{AR} \mathrm{WC} \mathrm{nozzle,} \mathrm{(b)} 425^{\circ} \mathrm{C} \mathrm{HT}$ WC nozzle, (c) $600^{\circ} \mathrm{C}$ HT WC nozzle, (d) $425^{\circ} \mathrm{C}$ AR PBI nozzle, and (e) $425^{\circ} \mathrm{C}$ HT PBI nozzle

powder deposition indicate the presence of both ferrite and martensite. The decrease of the (001) and (002) signals in the HT powder and the reemergence of the (001) plane suggests that shear-induced martensitic transformation could have occurred. While the presence of carbides was detected in both the AR and HT powders, there was no indication of growth in carbides present in the deposited samples, as the peaks across the powder and consolidated samples were proportionally equivalent in magnitude.

In a study of strain-induced martensitic transformation, Yang et al. ${ }^{69}$ reported that 30 to $35 \%$ cold work yielded the greatest level of austenite to martensite transformation. Comparing this work's microhardness data with approximated martensite, the data fall within the same regime, as compared with the work completed by Monrrabal et al.. ${ }^{70}$ It is thus understood that this material can exhibit this shear-induced phenomena, which is consistent with the highly kinetic deposition coupled with the XRD and microindentation characterization results.

\section{CONCLUSION}

This study explored the effects of heat-treating stainless-steel battlefield scrap powder for cold spray applications. Various heat treatments and processing conditions were employed, resulting in the following conclusions from this work:

- The recycled stainless-steel powder exhibited a skewed PSD, which was consistent with using a 
(a)

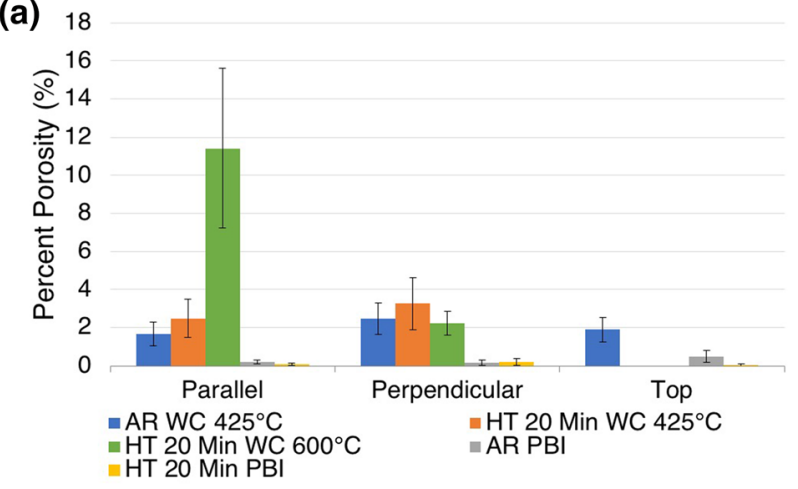

(b) 0.9

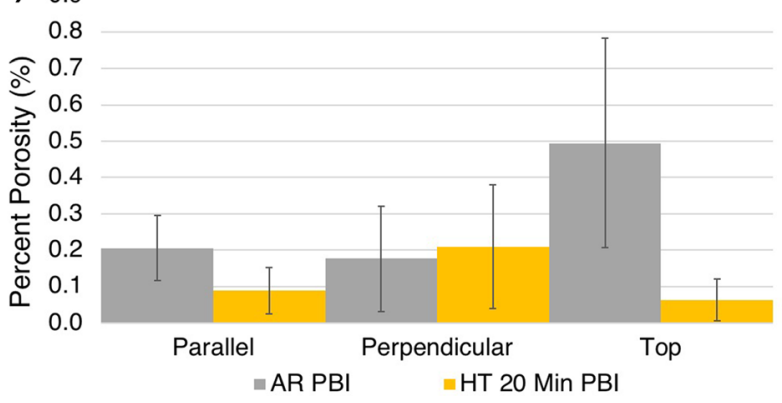

(c)

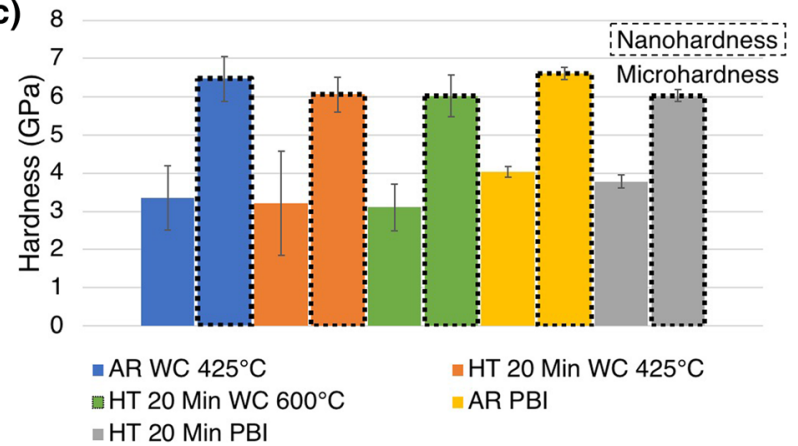

Fig. 6. (a) Porosity of deposition as function of spray direction, (b) enlarged porosity of PBI nozzle conditions, and (c) nanoindentation (dashed border) and microindentation (solid border) hardness of cold-sprayed samples

$45-\mu \mathrm{m}$ sieve without removing fines. Small carbon-rich plates were also present in the powder, which are likely contaminants from the recycling process. While this work does not confirm that the contamination or given PSD affect the cold spray deposition efficiency, it is likely that there will be a thermal size effect from the recycling process on the phases present in the powder.

- Guided by thermodynamic calculations using Thermo-Calc, the powder was subjected to several heat treatments. Each thermally processed powder was analyzed using SEM, XRD, and nanoindentation to monitor the phases present in the microstructure. Treatment was completed using a laboratory-scale TGA and an industrialscale furnace. While both methods were capable of transforming ferrite to austenite while held at $840^{\circ} \mathrm{C}$, only the furnace completely austenitized the powder due to the longer exposure time and slower cooling rates experienced in the furnace compared with the TGA.

- The AR and HT powders were sprayed using multiple nozzles and spray temperatures with the VRC GEN III system. The AR deposits exhibited extensive porosity and microcracking, as opposed to the virtually fully dense deposit from the HT powder. Based on this work's findings, the HT powder and PBI nozzle spray resulted in the best deposition.

- Analysis of the sprayed deposits using XRD indicated a potential shear-induced martensitic transformation. Given the high levels of plastic deformation associated with cold spray deposition, it is likely that the austenite in the powder transformed to martensite upon impact. This may serve as a beneficial side-effect of this work, as martensitic strengthening could prove useful in cold spray applications.

Future exploration will probe mechanical testing techniques and application-specific metrics of parts produced using reatomized scrap steel for cold spray. As the intended scope of applications generally fall within a corrosive or temperature-sensitive arena, testing methods will be followed to further validate the findings presented in this work and help qualify this scrap material and process parameters as a certified repair technique.

\section{OPEN ACCESS}

This article is licensed under a Creative Commons Attribution 4.0 International License, which permits use, sharing, adaptation, distribution and reproduction in any medium or format, as long as you give appropriate credit to the original author(s) and the source, provide a link to the Creative Commons licence, and indicate if changes were made. The images or other third party material in this article are included in the article's Creative Commons licence, unless indicated otherwise in a credit line to the material. If material is not included in the article's Creative Commons licence and your intended use is not permitted by statutory regulation or exceeds the permitted use, you will need to obtain permission directly from the copyright holder. To view a copy of this licence, visit http://creativecom mons.org/licenses/by/4.0/.

\section{REFERENCES}

1. V.K. Champagne, The Cold Spray Materials Deposition Process: Fundamentals and Applications (Cambridge, UK: Woodhead, 2007), pp. 1-7 and pp. 217-231.

2. D.L. Belsito, Application of computational thermodynamic and solidification kinetics to cold sprayable powder alloy design, Doctoral dissertation, Worcester Polytechnic Institute (2014).

3. V.K. Champagne, Jr., Investigation of the Effect of Oxides on the Critical Impact Velocity during the Cold Spray Process of High Purity Aluminum Powder, Doctoral dissertation, Worcester Polytechnic Institute (2018).

4. C.E. Walde, D.L. Cote, V.K. Champagne Jr, and R.D. Sisson Jr, J. Mater. Eng. Perform. 28, 601 (2019). 
5. L.E. Randaccio, Pre-heat treatment of gas atomized al 2024 powder and its effects on the properties of cold spray coatings, Master's thesis, Northeastern University, 2019.

6. C.E. Walde, K.L. Tsaknopoulos, V.K. Champagne Jr, and D.L. Cote, Metallogr. Microstruct. Anal. 8, 415 (2019).

7. K.L. Tsaknopoulos, C.E. Walde, V.K. Champagne Jr, and D.L. Cote, JOM 71, 435 (2019).

8. W.A. Story and L.N. Brewer, Metall. Mater. Trans. A 49, 446 (2018).

9. A. Sabard, H.L. de Villiers Lovelock, and T. Hussain, J. Therm. Spray Technol. 27, 145 (2018).

10. C.E. Walde, Thermal processing of powder aluminum alloys for additive manufacturing applications, Doctoral dissertation, Worcester Polytechnic Institute (2018).

11. K.L. Tsaknopoulos, Computational thermodynamic and kinetic modeling and characterization of phase transformations in rapidly solidified aluminum alloy powders, Doctoral dissertation, Worcester Polytechnic Institute (2019).

12. S.A. Tsukerman, Powder Metallurgy, 1st ed. (Oxford, UK: Pergamon, 1965).

13. Prasan K. Samal and Joseph W. Newkirk, ASM Handbook, Volume 7: Powder Metallurgy (Materials Park, OH: ASM International, 2015).

14. L.V.M. Anthony and R.G. Reddy, JOM 55, 14 (2003).

15. K. Sundberg, Y. Wang, B. Mishra, A. Carl, R. Grimm, A. Te, L. Lozeau, B. Sousa, R. Sisson, and D. Cote, Biomed. J. Sci. Tech. Res. 22, 16753 (2019).

16. R. Barua, Study of the structural properties and control of degradation rate for biodegradable metallic stents using cold spray, Doctoral dissertation, McGill University, 2015.

17. B. Al-Mangour, The use of cold sprayed alloys for metallic stents, Doctoral dissertation, McGill University, 2012.

18. J. Frattolin, A biomechanical evaluation of an iron and stainless steel 316L biodegradable coronary stent, Doctoral dissertation, McGill University, 2019.

19. B. Al-Mangour, P. Vo, R. Mongrain, E. Irissou, and S. Yue, J. Therm. Spray Technol. 23, 641 (2014).

20. F. Sevillano, P. Poza, C.J. Munez, S. Vezzu, S. Rech, and A. Trentin, J. Therm. Spray Technol. 22, 772 (2013).

21. K. Victor, Champagne, The Cold Spray Materials Deposition Process: Fundamentals and Applications (Cambridge, UK: Woodhead, 2007), p. 327.

22. Dennis J. Helfritch, in The Cold Spray Materials Deposition Process, ed. Victor K. Champagne, (Cambridge, UK: Woodhead, 2007), p. 315.

23. M.D. Trexler, R. Carter, W.S. de Rosset, D. Gray, D.J. Helfritch, and V.K. Champagne Jr, Mater. Manuf. Process. 27, 820 (2012).

24. M. Pepi, Report No. ARL-RP-0618, U.S. Army Research Laboratory, Aberdeen Proving Ground, MD, October 2017.

25. M. Pepi, T. Whalen, R. Brennan, M. Bratcher, and R. Riman, Report No. ARL-TR-7560, U.S. Army Research Laboratory, Aberdeen Proving Ground, MD, December 2015.

26. M. Pepi, N. Zander, and M. Gillan, JOM 70, 2359 (2018).

27. K. M. Sabo, B. T. Golesich, and M. L. Tims, in Proceedings of the 2018 Ground Vehicle Systems Engineering and Technology Symposium (Novi, MI: 2018).

28. V.K. Champagne Jr, J. Fail. Anal. Preven. 8, 164 (2008).

29. G.E. Moller, in Proceedings of the Offshore Technology Conference (Houston, TX: 1976).

30. R. Plaut, C. Herrera, D.M. Escriba, P.R. Rios, and A.F. Padilha, Mater. Res. 10, 453 (2007).

31. G.E. Totten, Steel Heat Treatment: Metallurgy and Technologies (Boca Raton, FL: CRC Press, LLC, 2006).

32. A. Kumar, S.B. Singh, and K.K. Ray, Mater. Sci. Eng., A 474,270 (2008)

33. S. Adachi and N. Ueda, Coatings 7, 87 (2017).

34. J. Vlcek, L. Gimeno, H. Huber, and E. Lugscheider, J. Therm. Spray Technol. 14, 125 (2005).

35. X. Meng, J. Zhang, J. Zhao, Y. Liang, and Y. Zhang, J. Mater. Sci. Technol. (Shenyang, China) 27, 809 (2011).

36. P. Codder, C. Verdy, C. Coddet, F. Debray, and F. Lecouturier, Surf. Coat. Technol. 277, 74 (2015).
37. L.N. Brewer, J.F. Schiel, E.S.K. Menon, and D.J. Woo, Surf. Coat. Technol. 334, 50 (2018).

38. B. Dikici, H. Yilmazer, I. Ozdemir, and M. Isik, J. Therm. Spray Technol. 25, 704 (2016).

39. B. Dikici and M. Topuz, Prot. Met. Phys. Chem. Surf. 54, 333 (2018).

40. S. Yin, J. Cizek, X. Yan, and R. Lupoi, Surf. Coat. Technol. 370, 353 (2019).

41. S. Yin, X. Yan, R. Jenkins, C. Chen, E.-M. Kazasidis, M. Liu, M. Kuang, and R. Lupo, J. Mater. Process. Technol. 273, 116248 (2019).

42. Y. Xie, M.P. Planche, R. Raoelison, H. Liao, X. Suo, and P. Herve, J. Therm. Spray Technol. 25, 123 (2016).

43. X. Chu, R. Chakrabarty, H. Che, L. Shang, P. Vo, J. Song, and S. Yue, Surf. Coat. Technol. 337, 53 (2018).

44. X. Chu, H. Che, P. Vo, R. Chakrabarty, B. Sun, J. Song, and S. Yue, Surf. Coat. Technol. 324, 353 (2017).

45. ASTM Standard E1097-12, ASTM Book of Standards (West Conshohocken, PA: ASTM International (2017).

46. ASTM Standard E1019-18, ASTM Book of Standards (West Conshohocken, PA: ASTM International (2018).

47. ASTM Standard A240/A240M-19, ASTM Book of Standards (West Conshohocken, PA: ASTM International (2019).

48. V.K. Champagne, A. Nardi, and D. Cote, Int. J. Powder Metall. 51, 37 (2015).

49. W. Wong, P. Vo, E. Irissou, A.N. Ryabinin, J.G. Legoux, and S. Yue, J. Therm. Spray Technol. 22, 1140 (2013).

50. W. Wong, E. Irissou, A.N. Ryabinin, J.G. Legoux, and S. Yue, J. Therm. Spray Technol. 20, 213 (2011).

51. N. Cinca, J.M. Rebled, S. Estradé, F. Peiró, J. Fernández, and J.M. Guilemany, J. Alloys Compd. 554, 89 (2013).

52. V.N.V. Munagala, V. Akinyi, P. Vo, and R.R. Chromik, J. Therm. Spray Technol. 27, 827 (2018).

53. P.C. King and M. Jahedi, Appl. Surf. Sci. 256, 1735 (2010).

54. M. Behulova, R. Moravcik, M. Kusy, L. Caplovic, P. Grgac, and L. Stancek, Mater. Sci. Eng., A 304, 540 (2001).

55. P. Grgač, M. Behúlová, and R. Moravčík, Mater. Res. 15, 705 (2012).

56. M.J. Heiden, L.A. Deibler, J.M. Rodelas, J.R. Joepke, D.J. Tung, D.J. Saiz, and B.H. Jared, Addit. Manuf. 25, 84 (2019).

57. M. Kusy, L. Caplovic, P. Grgac, and A. Vyrostkova, J. Mater. Process. Technol. 157, 729 (2004)

58. M. Pavlickova, D. Vojtech, P. Stolar, and P. Jurci, Powder Metall. Prog. (Warsaw, Pol.) 2, 81 (2002).

59. M. Yang, C. Song, Y. Dai, L. Zhu, K. Li, and Q. Zhai, J. Iron. Steel Res. Int. 18, 75 (2011).

60. L.E. Eiselstein, O.A. Ruano, and O.D. Sherby, J. Mater. Sci. 18, 483 (1983).

61. A. Zambon, B. Badan, A.F. Norman, A.L. Greer, and E. Ramous, Mater. Sci. Eng., A 226, 119 (1997).

62. K. Opatová, I. Zetková, and L. Kučerová, Materials 13, 956 (2020).

63. P. Grgac, R. Moravcik, M. Kusy, I. Toth, M. Miglierini, and E. Illekova, Mater. Sci. Eng., A 375, 581 (2004).

64. M. Miglierini, Czech J. Phys. 55, 813 (2005).

65. M. Miglierini, A. Lančok, and M. Kusý, in Proceedings of the International Symposium on the Industrial Applications of the Mösbauer Effect (Budapest, HU: 2008).

66. S.A. Tukur, M.S. Dambatta, A. Ahmed, and N.M. Mu'az, Int. J. Innov. Res. Sci. Eng. Technol. 3, 9516 (2014).

67. W.A. Story, D.J. Barton, B.C. Hornbuckle, K.A. Darling, G.B. Thompson, and L.N. Brewer, Materialia 3, 239 (2018).

68. M. Tului, C. Bartuli, A. Bezzon, A.L. Marino, F. Marra, S. Matera, and G. Pulci, Metals 9, 678 (2019).

69. F. Yang and J.L. Huang, Trans. Mater. Heat Treat. 3, 104 (2012).

70. G. Monrrabal, A. Bautista, S. Guzman, C. Gutierrez, and F. Velaasco, J. Mater. Res. Technol. 8, 1335 (2019).

Publisher's Note Springer Nature remains neutral with regard to jurisdictional claims in published maps and institutional affiliations. 